\title{
Comparative Analysis of Compact Heat Exchangers for Application as the Intermediate Heat Exchanger for Advanced Nuclear Reactors
}

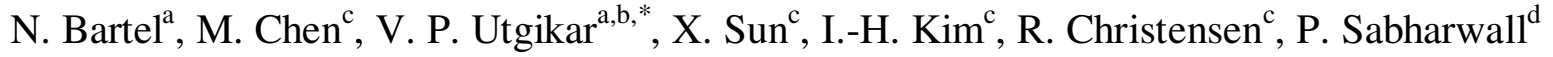 \\ ${ }^{a}$ Nuclear Engineering Program, University of Idaho, Moscow, ID 83844, USA \\ ${ }^{\mathrm{b}}$ Department of Chemical and Materials Engineering, University of Idaho, Moscow, ID 83844, USA \\ ${ }^{c}$ Nuclear Engineering Program, Department of Mechanical and Aerospace Engineering, The Ohio State \\ University, Columbus, $\mathrm{OH} 43210$, USA. \\ ${ }^{\mathrm{d}}$ Idaho National Laboratory, Idaho Falls, ID 83415, USA
}

*Corresponding author: Tel.:1-208-885-6970, Fax: 1-208-885-7462,

e-mail:vutgikar@uidaho.edu 


\section{ABSTRACT}

A comparative evaluation of alternative compact heat exchanger designs for use as the intermediate heat exchanger in advanced nuclear reactor systems is presented in this article. Candidate heat exchangers investigated included the Printed Circuit Heat Exchanger (PCHE) and Offset Strip-Fin Heat Exchanger (OSFHE). Both these heat exchangers offer high surface area to volume ratio (a measure of compactness $\left.\left[\mathrm{m}^{2} / \mathrm{m}^{3}\right]\right)$, high thermal effectiveness, and overall low pressure drop. Helium-helium heat exchanger designs for different heat exchanger types were developed for a $600 \mathrm{MW}$ thermal advanced nuclear reactor. The wavy channel PCHE with a $15^{\circ}$ pitch angle was found to offer optimum combination of heat transfer coefficient, compactness and pressure drop as compared to other alternatives. The principles of the comparative analysis presented here will be useful for heat exchanger evaluations in other applications as well.

Keywords: Advanced Nuclear Reactor; Intermediate Heat Exchanger; printed circuit heat exchanger (PCHE); Offset Strip-Fin Heat Exchanger (OSFHE); Thermal-hydraulic design; Heat Exchange Compactness 


\section{Introduction}

Advanced reactors, such as the High Temperature Gas-Cooled Reactor (HTGR) or Advanced High Temperature Reactor (AHTR) from the Generation IV Program, are required to deliver electricity and process heat with high efficiency. The electric power production may be through a high-pressure steam generator (Rankine Cycle) or a direct- or indirect-cycle gas turbine (Brayton Cycle). The process heat applications may include co-generation, coal-to-liquids conversion, and synthesis of chemical feedstock. The process heat applications of these advanced reactors are critically dependent upon an effective intermediate heat exchanger (IHX), which is a key component transferring heat from the primary coolant to a secondary coolant [1]. A schematic of the advanced reactor-IHX-power/heat application is shown in Figure 1. The primary loop in the system conducts the thermal energy from the nuclear reactor to the IHX, and a secondary medium transfers this energy to the power generation or process application via the secondary loop. The overall performance of the system is highly dependent upon the IHX, requiring it to operate at high efficiency. The IHX also serves as the primary coolant boundary and must be robust enough to integrity under normal conditions.

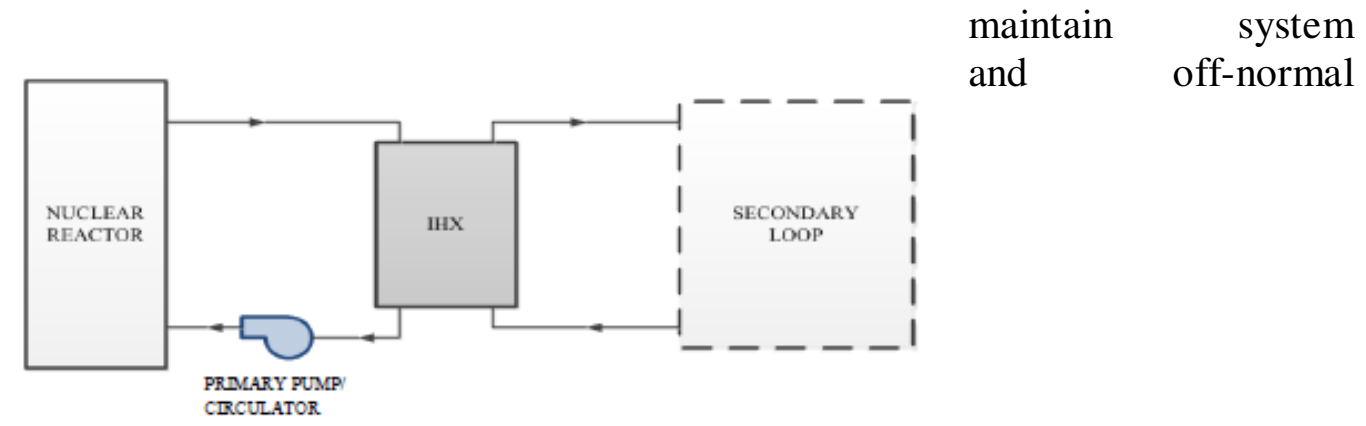

Fig. 1. Advanced Reactor-IHX-Secondary Application System

Several investigators have looked at various heat exchanger configurations for use as the IHX. Compact heat exchangers are particularly attractive candidates as they have high effectiveness and low heat loss due to their high heat transfer area per unit volume of the exchanger. In addition, compact heat exchangers, such as the printed circuit heat exchanger (PCHE) or offset strip-fin heat exchanger (OSFHE) operate in the laminar flow regime and have low pressure drops, minimizing the energy requirements for coolant circulation. Kim and No [2] investigated the performance of a PCHE in a Helium-Helium test loop and found an effectiveness of 95\%. Ishizuka, et al. [3] investigated the performance in a super-critical $\mathrm{CO}_{2}$ loop and found an effectiveness of greater than $98 \%$. The use of these heat exchangers can result in improved performance of the system shown in Fig. 1.

The objective of the present paper is to present a comparison of the steady state designs of a wavychannel PCHE and an OSFHE for a 600 MWth nuclear reactor. These two types of heat exchangers are described briefly followed by the steady state models and resulting thermal-hydraulic designs. A comparative analysis of the two designs is also presented which would help in decision-making related to the advanced nuclear reactor systems.

\section{Heat Exchanger Geometry}

\subsection{Wavy-Channel PCHE}


A PCHE is a type of compact heat exchanger where the flow channels are photo-chemically etched on one side of thin plates. The fluid channels are typically semicircular in cross-section. These plates are then stacked on top of each other and formed into a heat exchanger core through a diffusion bonding process that includes a thermal soaking period to allow grain growth. This diffusion bonding process enables an interface-free join between the plates and gives the base material strength and a very high pressure containment capability [4]. A cross-section of a single-bank arrangement consists of hot and cold fluids flowing through the flow channels on alternate plates as shown in Figure 2 (a). It should be noted that the diffusion bonding process will eliminate the boundaries between the plates, forming a monolithic block with semicircular flow channels in it. The plenum arrangement to accomplish this flow configuration is shown in Figure 2 (b).

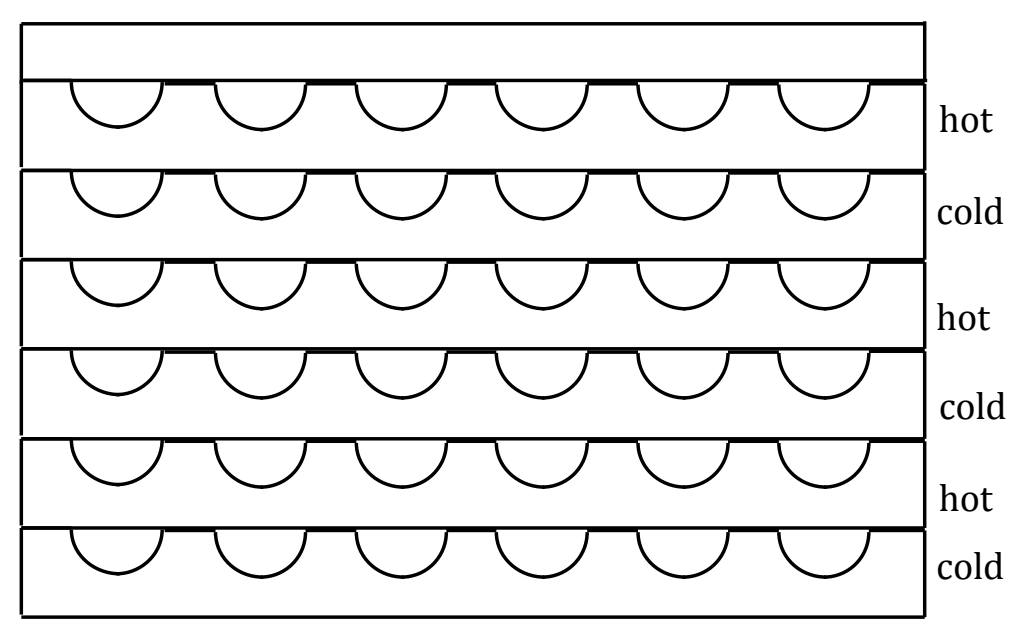

(a)

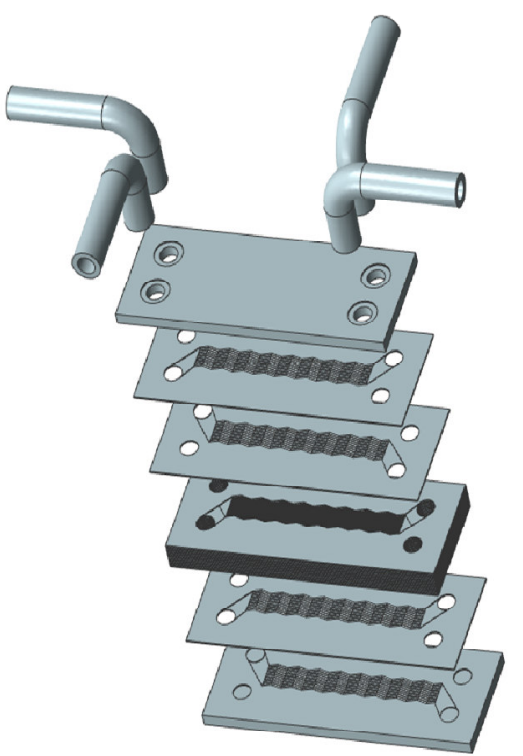

(b)

Figure 2. Single-Bank, in-line PCHE

In the countercurrent flow arrangement, the cold and hot fluids flow in opposite directions on the adjacent plates. The individual channels are etched in a zig-zag configuration in the wavy channel PCHE as shown in Fig. 3. The geometry of the wavy channel is determined by the pitch angle $\phi$ and single pitch length as indicated in the figure.

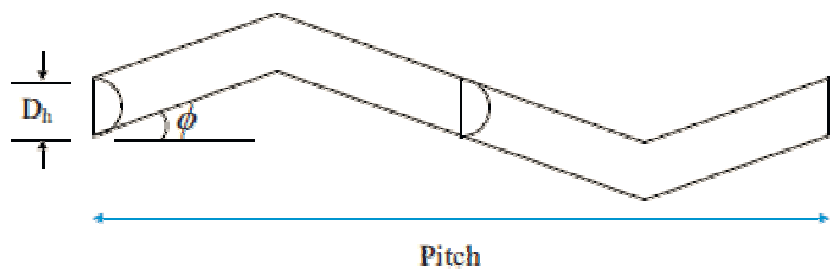

Figure 3. Wavy Channel Geometry [3]

A summary of the PCHE geometrical parameters investigated in this study is shown in Table 1. The channel pitch was maintained at $24.6 \mathrm{~mm}$, while three different pitch angles of $10^{\circ}, 15^{\circ}$ and $20^{\circ}$ were investigated. 
Table 1. PCHE Geometry

\begin{tabular}{ll}
\hline Variable & Dimension \\
\hline Channel Diameter & 1.51 \\
Hydraulic Diameter & 0.922 \\
$\boldsymbol{\phi}$ & $0^{\circ}, 10^{\circ}, 15^{\circ}$, \\
Channel Pitch [mm] & 24.6 \\
Plate Thickness [mm] & 1.46 \\
Plate Length [m] & 0.2 \\
\hline
\end{tabular}

\subsection{OSFHE}

An OSFHE consists of flow channels that have a number of rectangular fins of uniform thickness arrayed in the flow direction. Alternate fins along the flow direction are in a staggered configuration, with the offset between the upstream and downstream fins equal to half-fin spacing normal to the flow direction. The geometry of a unit cell of the offset strip-fin channel is shown in Fig. 4 (a), with the characteristic dimensional parameters - fin length $l$, fin thickness $t_{f}$, fin spacing (pitch in span-wise direction $P_{x}$ ) - clearly identified. The height of the fin is same as the channel height $c h$, and the length of the unit cell is double the pitch in the flow direction $\left(P_{y}\right)$, which is the center-to-center longitudinal distance between consecutive fins. The unit cell repeated in both the flow direction and the direction normal to the flow forms a single layer of flow channels. OSFHE is formed by stacking a number of such layers as shown in Fig. 4 (b). As in the case of PCHE, cold and hot fluid flow through alternate layers of the OSFHE. The geometrical parameters of the OSFHE used in this study are shown in Table 2.

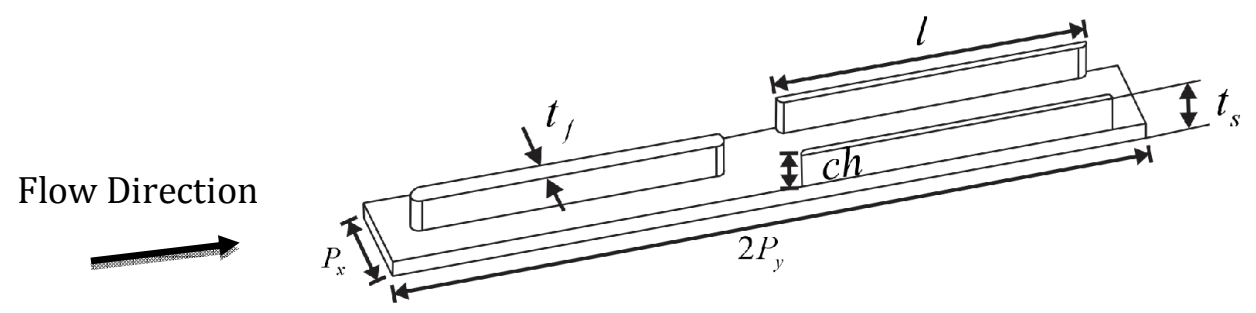

(a)

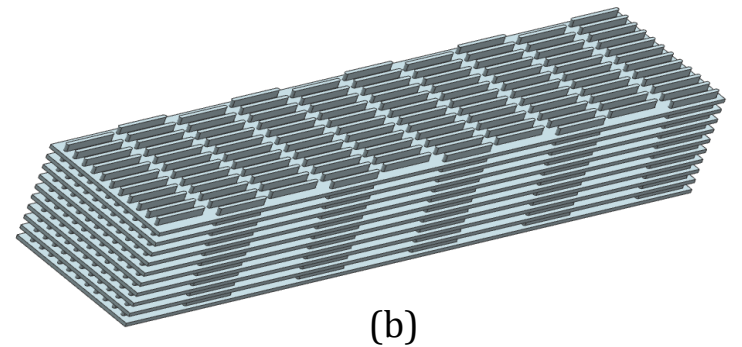

(b)

Fig. 4. Schematic of the Scaled-down Offset Strip-fin PCHE and One Unit Cell (a) Unit cell (b) Cell Stack 
Table 2. Offset Strip-fin Geometry

\begin{tabular}{cc}
\hline Variable & Dimension, [mm] \\
\hline Channel Height, $\boldsymbol{c h}$ & 1.2 \\
Fin Thickness, $\boldsymbol{t}_{\boldsymbol{f}}$ & 0.6 \\
Fin Length, $\boldsymbol{l}$ & 10 \\
Plate Thickness, $\boldsymbol{t}_{\boldsymbol{s}}$ & 1.8 \\
Pitch in Span-wise Direction, $\boldsymbol{P}_{\boldsymbol{x}}$ & 2 \\
Pitch in Flow Direction, $\boldsymbol{P}_{\boldsymbol{y}}$ & 12 \\
\hline
\end{tabular}

\section{Design Methodology}

Alternative IHX designs for the two types of heat exchangers described above were developed for a high temperature gas reactor (HTGR). The basic design assumptions are as follows:

- the working fluid flow rates in the primary and secondary loops are equivalent and it thus is a balanced-flow heat exchanger

- the heat exchanger operates at steady state,

- flow distribution in each channel is uniform,

- the hot and cold plates have equivalent geometry,

- the cross section of the flow passage is approximately semicircular (only for PCHE),

- heat loss from the exchanger is neglected.

The design methodology used for the PCHE/OSFHE is summarized below:

- The required operational conditions are defined as shown in Table 3.

Table 3. Operating Conditions

\begin{tabular}{|c|c|c|}
\hline \multirow[t]{2}{*}{ Parameters } & Hot Channel & Cold Channel \\
\hline & Out & Out \\
\hline Fluid & Helium & Helium \\
\hline Nominal Duty [MW] & & 00 \\
\hline $\boldsymbol{T}\left[{ }^{\circ} \mathrm{C}\right]$ & 543 & 776 \\
\hline $\boldsymbol{P}[\mathrm{MPa}]$ & 7 & 7.97 \\
\hline$\dot{\boldsymbol{m}}[\mathrm{kg} / \mathrm{h}]$ & 450 & 450 \\
\hline $\boldsymbol{\rho}\left[\mathrm{kg} / \mathrm{m}^{3}\right]$ & 3.5365 & 4.122 \\
\hline $\boldsymbol{c}_{\boldsymbol{p}}[\mathrm{kJ} / \mathrm{kg}-\mathrm{K}]$ & 5.193 & 5.193 \\
\hline $\boldsymbol{\mu}[\mathrm{Pa}-\mathrm{s}]$ & $4.29 \mathrm{e}-05$ & $4.12 \mathrm{e}-05$ \\
\hline $\operatorname{Pr}$ (Prandtl number) & 0.67 & 0.67 \\
\hline
\end{tabular}

- A heat balance between the hot and cold channels is obtained,

- Initial geometry of the heat exchanger is defined. This includes number of channels/per plate, channel length, and number of plates. The channel dimensions have been described above.

- The individual cold and hot side heat transfer coefficients are estimated using the correlations presented below in sections 3.1 and 3.2. The overall heat transfer coefficient, $U$, is calculated 
from the two convective heat transfer coefficients and including the contribution by the conductive resistance of the plate.

- The required surface area for the PCHE/OSFHE is calculated using the design thermal duty,

- The geometry meeting the required surface area is found, and compared to the initial value.

- The friction factors and pressure drops for the two fluids are determined.

- If the pressure drop exceeds $1 \%$ of the inlet pressure for the fluids, then the geometry is revised and the above design steps are repeated.

The procedure is repeated iteratively until the design geometries converge and the pressure drop criteria are satisfied.

\subsection{Design of Wavy PCHE}

\subsubsection{Reynolds Number}

The Reynolds number for the hot and cold fluids is calculated by:

$$
R e=\frac{\dot{m} D_{h}}{\mu A_{f}}
$$

Where, $\dot{m}$ is the mass flow rate in the channel; $D_{h}$ is the hydraulic diameter of the semicircular channel; $\mu$ is the viscosity of the fluid; and $A_{f}$ is the total flow area.

The low mass flow rate of the system guarantees that the fluid flow is well within the laminar regime. For a semicircular duct, the critical Reynolds number for transitional flow occurs at a Reynolds number greater than 2200 [4].

\subsubsection{Heat Balance}

A heat given up by the hot fluid is given by equation 2, while that gained by the cold fluid is given by equation 3. The nominal heat duty of the heat exchanger is taken to the average of these values as shown in equation 4.

$$
\begin{aligned}
& \dot{Q}_{h}=\dot{m}_{h} c_{p, h}\left(T_{h, i}-T_{h, o}\right) \\
& \dot{Q}_{c}=\dot{m}_{c} c_{p, c}\left(T_{c, o}-T_{c, i}\right) \\
& \dot{Q}=\frac{1}{2}\left(\dot{Q}_{h}+\dot{Q}_{c}\right)
\end{aligned}
$$

where $c_{p}$ is the specific heat capacity of the hot or cold fluid and $T$ is the fluid temperature of the hot (subscript $h$ ) or cold (subscript $c$ ) fluid. The subscripts $i$ and $o$ denote the inlet and outlet of the heat exchanger fluid flow passages. For an ideal heat exchanger with no losses, $\dot{Q}_{h}=\dot{Q}_{c}=\dot{Q}$.

\subsubsection{Overall Heat Transfer Coefficient}

The overall heat transfer coefficient, $U$, of the PCHE can be calculated from,

$$
U=\frac{1}{h_{h}}+\frac{t_{w}}{k_{w}}+\frac{1}{h_{c}}
$$

where $h_{h}$ and $h_{c}$ are the hot and cold channel convection heat transfer coefficients; $t_{w}$ is the average wall thickness; and $k_{w}$ is the wall thermal conductivity. The average wall thickness is used in this calculation due to the variance in thickness between the hot and cold plates. The average wall thickness is $0.9075 \mathrm{~mm}$. The heat transfer coefficient are calculated from the correlations for the Nusselt number, which is the ratio of convective to conductive heat transfer within a fluid. For a straight channel PCHE in fully-developed laminar flow, Hesselgreaves [4] recommends the following correlation, 


$$
N u_{H 1}=4.089
$$

Where, $H 1$ subscript indicates that an axially constant wall heat flux with circumferentially constant wall temperature exists. This correlations needs to be modified for the calculation of the Nusselt number for the wavy channel PCHE, as a continual interruption of the boundary layer resulting in reverse flows and eddies in the wavy channel enhances the Nusselt number. Kim and No [2] have proposed a correlation, which modified (6) with the use of fitting constants. This modified correlation incorporates the effects of the wavy channels and is valid under laminar flow conditions $(R e<2200)$ is:

$$
N u=4.089+c \cdot R e^{d}
$$

where the fitting constants $c$ and $d$ are dependent on the pitch angle and pitch length of the wavy channel [2]. The fitting constants are listed in Table 4, with low root mean-square (RMS) error reported by Kim and No [2] indicating the goodness-of-fit of model equation 7.

Table 4. Nusselt Number Fitting Constants

\begin{tabular}{cccc}
\hline$\phi$ & $c$ & $d$ & $\begin{array}{c}\text { RMS } \\
\text { error }\end{array}$ \\
\hline $10^{\circ}$ & 0.0022 & 0.9984 & $0.459 \%$ \\
\hline $15^{\circ}$ & 0.0054 & 0.9136 & $1.849 \%$ \\
$20^{\circ}$ & 0.0089 & 0.8671 & $1.589 \%$ \\
\hline
\end{tabular}

\subsubsection{Fanning Friction Factor and Pressure Drop}

The Fanning friction factor for a straight, semicircular duct under laminar flow conditions for semicircular channels $(R e<2200)$ is given by [4],

$$
f \cdot R e=15.78
$$

This correlation needs to be modified to incorporate the effect of the wavy channel geometry. The improved correlation that includes the effects of the wavy channels interrupting the boundary layer applicable under laminar flow conditions $(R e<2200)$ is [2],

$$
f_{P C H E} \cdot R e=15.78+a \cdot R e^{b}
$$

Where, the fitting constants $a$ and $b$ are dependent upon the pitch angle and pitch length of the wavy channel. These fitting constants, with low RMS error indicating the goodness-of-fit, are shown in Table 4.

The pressure drop for the wavy channel PCHE is found by using the friction factor correlation (9) developed by Kim and No [2] that includes the effects of wavy channels.

$$
\Delta P=4 f_{P C H E} \frac{L_{c}}{D_{h}} \frac{1}{2} \rho v^{2}
$$

where $L_{c}$ is the channel length; $\rho$ is the fluid density; and $v$ is the mean fluid velocity of the channel. Equation (10) can be used to calculate the overall pressure drop across the PCHE with wavy channels 


Table 5. Fanning Factor Fitting Constan
\begin{tabular}{cccc}
\hline$\phi$ & $a$ & $b$ & $\begin{array}{c}\text { RMS } \\
\text { error }\end{array}$ \\
\hline $10^{\circ}$ & 0.0178 & 0.908 & $1.319 \%$ \\
$15^{\circ}$ & 0.0646 & 0.8102 & $1.104 \%$ \\
$20^{\circ}$ & 0.0892 & 0.8136 & $0.876 \%$ \\
\hline
\end{tabular}

\subsection{Design of OSFHE}

The design method of offset strip-fin PFHE uses the same procedure outlined in section 3.1, with the only difference being in the correlations. The correlations listed below developed by Manglik and Bergels [5] are the most widely used. The equations for the Fanning Friction Factor, $f$, and the Colburn factor, $j$, are correlated to the experimental data within $\pm 20 \%$ for $120<\operatorname{Re}<10,000$ and $0.5<\operatorname{Pr}<$ 1.5 .

$$
\begin{aligned}
& f=9.6243 \mathrm{Re}^{-0.7422} \alpha^{-0.1856} \delta^{0.3053} \gamma^{-0.2659}\left(1+7.669 \times 10^{-8} \mathrm{Re}^{4.429} \alpha^{0.92} \delta^{3.767} \gamma^{0.236}\right)^{-1} \\
& j=0.6522 \mathrm{Re}^{-0.5403} \alpha^{-0.1541} \delta^{0.1499} \gamma^{-0.0678}\left(1+5.269 \times 10^{-5} \mathrm{Re}^{1.34} \alpha^{0.504} \delta^{0.456} \gamma^{-1.055}\right)^{-1}
\end{aligned}
$$

where the parameters $\alpha, \delta$ and $\gamma$ are defined as $\alpha=\left(P_{x}-t_{f}\right) / c h, \delta=t_{f} / l, \gamma=t_{f} /\left(P_{x}-t_{f}\right)$. The heat transfer coefficient of the exchanger can be found with the Colburn factor shown in below, and the pressure drop from equation (10).

$$
j=\mathrm{Co}=\mathrm{StPr}^{2 / 3}=\frac{\mathrm{Nu}}{\operatorname{RePr}^{1 / 3}}
$$

\section{Results and Discussion}

\subsection{Wavy Channel PCHE Design}

The results for the experimental designs have been tabulated for comparison in this section. The wavy channel pitch length is constant at $24.6 \mathrm{~mm}$ with pitch angles of $10^{\circ}, 15^{\circ}$, and $20^{\circ}$.

\subsubsection{Nusselt Number and Exchanger Details}

A comparison of the maximum Nusselt numbers for the straight channel and wavy channel Nusselt numbers are shown in Table 6.

Table 6. Nusselt Number Comparison

\begin{tabular}{lccc}
\hline PCHE Design & \multicolumn{2}{c}{ Nusselt Number } & $\begin{array}{c}\% \text { Avg. } \\
\text { Increase from } \\
\text { Straight }\end{array}$ \\
\hline Straight Channel & 4.089 & 4.089 & - \\
$10^{\circ}$ Wavy Channel & 8.27 & 8.34 & 103 \\
$15^{\circ}$ Wavy Channel & 9.22 & 9.30 & 127 \\
$20^{\circ}$ Wavy Channel & 10.31 & 10.39 & 153 \\
\hline
\end{tabular}

The detailed design results for the above alternatives are shown in Table 7. 
Table 7. PCHE Design Results

\begin{tabular}{lcccc}
\hline Parameter & Straight & $10^{\circ}$ & $15^{\circ}$ & $20^{\circ}$ \\
\hline LMTD $\left[{ }^{\circ} \mathrm{C}\right]$ & 23 & 23 & 23 & 23 \\
$U\left[\mathrm{~W} / \mathrm{m}^{2}-\mathrm{K}\right]$ & 551 & 1089 & 1208 & 1341 \\
Heat Transfer Area $\left[\mathrm{m}^{2}\right]$ & $5.69 \mathrm{e}+4$ & $2.41 \mathrm{e}+04$ & $2.14 \mathrm{e}+04$ & $1.92 \mathrm{e}+04$ \\
Core width $[\mathrm{m}]$ & 5.1625 & 4.2750 & 4.2750 & 4.275 \\
Core length $[\mathrm{m}]$ & 1.000 & 1.000 & 1.000 & 1.000 \\
Number of Plates & 6180 & 5000 & 4220 & 3720 \\
Volume $\left[\mathrm{m}^{3}\right]$ & 52 & 34.83 & 29.14 & 25.92 \\
Compactness $\left[\mathrm{m}^{2} / \mathrm{m}^{3}\right]$ & 1094 & 689 & 727 & 740 \\
\hline
\end{tabular}

\subsubsection{Pressure Drop}

A comparison of the maximum pressure drop for a straight channel and wavy channel PCHE designs are shown in Table 8.

Table 8. Overall Pressure Drop Comparison

\begin{tabular}{|c|c|c|c|}
\hline \multirow[t]{2}{*}{ PCHE Design } & \multicolumn{2}{|c|}{$\frac{\text { Pressure Drop }}{(\mathrm{kPa})}$} & \multirow{2}{*}{$\begin{array}{c}\% \text { Avg. } \\
\text { Increase from } \\
\text { Straight }\end{array}$} \\
\hline & Hot & Cold & \\
\hline Straight Channel & 8.05 & 6.8 & - \\
\hline $10^{\circ}$ Wavy Channel & 32.9 & 27.9 & 309 \\
\hline $15^{\circ}$ Wavy Channel & 46.2 & 39.3 & 476 \\
\hline $20^{\circ}$ Wavy Channel & 64.4 & 54.9 & 704 \\
\hline
\end{tabular}

\subsection{OSFHE Design}

In general, a large IHX consists of many modules, which are made of several blocks. There are some geometric limitations for the block due to the limited capabilities of industry: maximum plate width and non-flow length are $0.6 \mathrm{~m}$ and flow length is $1.5 \mathrm{~m}$ [3]. A single block thus has maximum dimensions of $1.5 \mathrm{~m} \times 0.6 \mathrm{~m} \times 0.6 \mathrm{~m}$. A number of such blocks can be combined into a module. The non-flow length of the module is $3 \mathrm{~m}$ when one module consists of five blocks, as shown in Fig. 5. Increasing the number of modules reduces operating costs while increasing the capital cost. The number of modules in the prototypic design of the OSFHE is 16, with each module having a heat duty of $37.5 \mathrm{MW}$. The associated flow length and Reynolds number are $1.176 \mathrm{~m}$ and 2140, respectively. The resultant design is summarized in Table .

Table 9. Thermal Hydraulic Design of OSFHE

\begin{tabular}{llllll}
\hline Parameter & Unit & Value & Parameter & Unit & Value \\
\hline Hot side Reynolds number & - & 2140 & Hot side Nusselt number & - & 17 \\
Cold side Reynolds number & - & 2174 & Cold side Nusselt number & - & 17.1 \\
Hot side mean velocity & $\mathrm{m} / \mathrm{s}$ & 17.8 & Hot side heat transfer coefficient & $\mathrm{W} / \mathrm{m}^{2}-\mathrm{K}$ & 4398.3 \\
Cold side mean velocity & $\mathrm{m} / \mathrm{s}$ & 15.3 & Cold side heat transfer coefficient & $\mathrm{W} / \mathrm{m}^{2}-\mathrm{K}$ & 4361.4 \\
Hot side hydraulic diameter & $\mathrm{mm}$ & 1.3 & Overall heat transfer coefficient & $\mathrm{W} / \mathrm{m}^{2}-\mathrm{K}$ & 1706.8 \\
Cold side hydraulic diameter & $\mathrm{mm}$ & 1.3 & Heat Transfer Area & $\mathrm{m}^{2}$ & $1.52 \times 10^{4}$ \\
LMTD & ${ }^{\circ} \mathrm{C}$ & 23 & Volume & $\mathrm{m}^{3}$ & 33.9 \\
Hot side pressure drop & $\mathrm{kPa}$ & 73.5 & Compactness & $\mathrm{m}^{2} / \mathrm{m}^{3}$ & 447 \\
Cold side pressure drop & $\mathrm{kPa}$ & 62.7 & Flow length & $\mathrm{m}^{2}$ & 1.176 \\
\hline
\end{tabular}




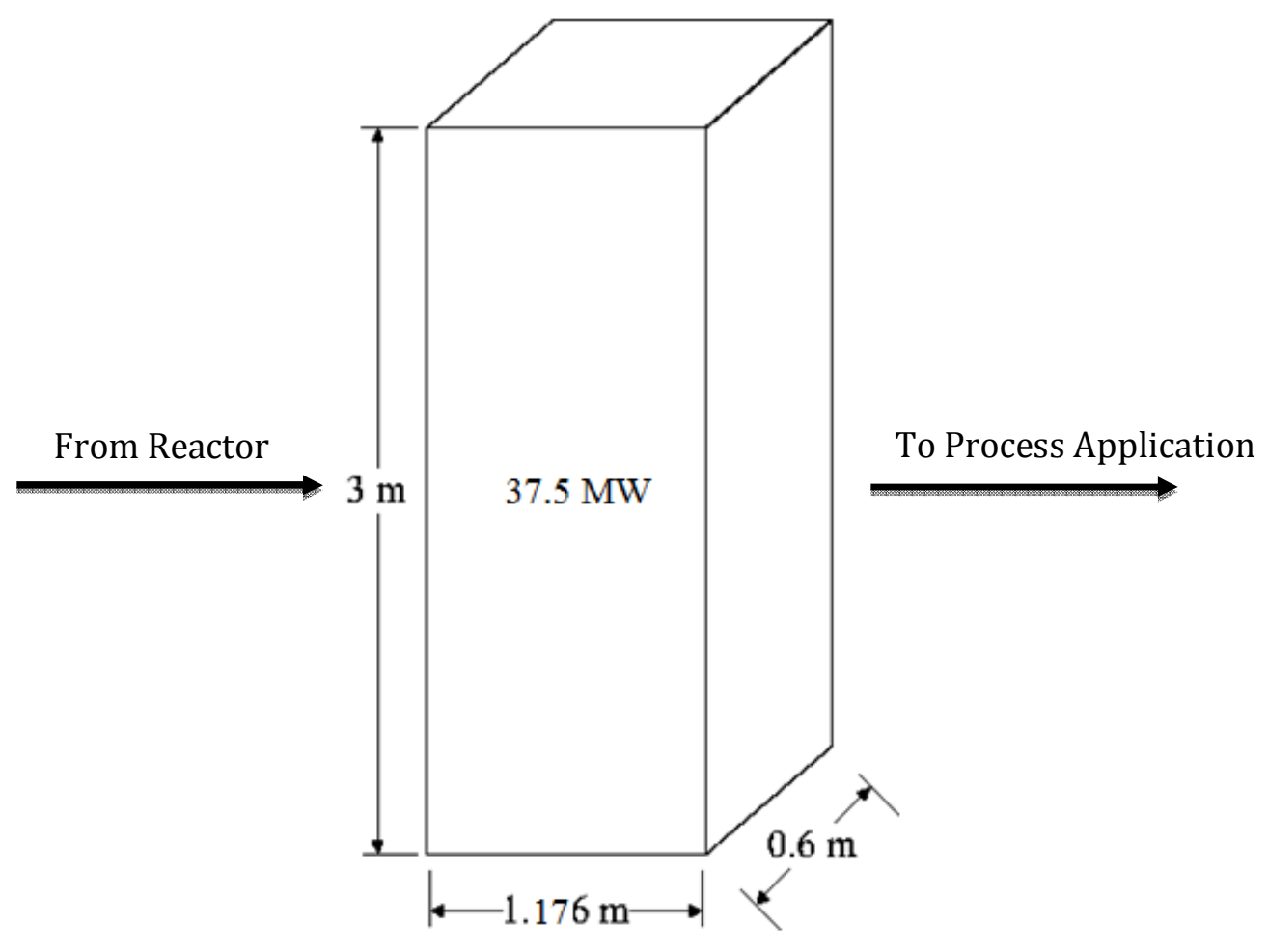

Fig. 5. Schematic of a Single OSFHE Module showing the Dimensions

\subsection{Comparative Analysis}

\subsubsection{Heat Transfer Characteristics}

It can be seen that changing the channel configuration from straight run to wavy results in a significant increase in the Nusselt numbers and the overall heat transfer coefficient. A channel with the pitch angle of $10^{\circ}$ offers a heat transfer coefficient that is almost twice that offered by the straight channel. Increasing the pitch angle further results in a still greater increase in the heat transfer coefficient. The higher Nusselt number, and increased heat transfer coefficient can be attributed to increased turbulence through the disruption of boundary layer. The total heat transfer area needed decreases substantially due to the increase in the heat transfer coefficient. Heat transfer area needed for the wavy channel PCHE with the pitch angle of $10^{\circ}$ is approximately $58 \%$ lower than that for the straight channel PCHE. Changing the angle from $10^{\circ}$ to $15^{\circ}$ results in a further reduction of $11 \%$ in the area. A further reduction of $10 \%$ is possible by increasing the pitch angle by an additional $5^{\circ}$. The OSFHE, due to its flow geometry offers the highest Nusselt number, resulting in the overall heat transfer coefficient that is three-times that in the straight channel PCHE, and 25\% higher than that offered by the wavy channel PCHE with the pitch angle of $20^{\circ}$. The area needed is lowest for the OSFHE.

\subsubsection{Pressure Drop}

The increased heat transfer coefficient in the wavy channel PCHE is associated with a penalty of higher pressure drop. The pressure drops in the wavy channel PCHE with $10^{\circ}$ pitch angle are three times as 
much as those in the straight channel PCHE. Increasing the pitch angle by $5^{\circ}$ (from $10^{\circ}$ to $15^{\circ}$, and from $15^{\circ}$ to $20^{\circ}$ ) results in increases of $\sim 50 \%$ in each step. The pressure drops in the OSFHE are higher by $15 \%$ than those in the $20^{\circ}$ pitch angle wavy channel PCHE. The pumping costs are accordingly going to be highest for the OSFHE.

\subsubsection{Volume and Compactness of Exchangers}

Another key criterion for the selection of heat exchangers is the exchanger volume which determines the footprint of the unit, and its compactness which is the specific heat transfer area (heat transfer area per unit volume) offered by the heat exchanger. Higher the compactness, lower is the heat exchanger volume requirements for the IHX. An exchanger with a higher compactness is preferable to one with a low compactness value, as the smaller volume affords a greater flexibility regarding the positioning of the IHX in the overall plant layout. As seen from Tables 7 and 9, the straight channel PCHE and the OSFHE have the highest and the lowest compactness, respectively. The compactness of the wavy channel PCHEs increases with the pitch angle, increasing by $5.5 \%$ from $10^{\circ}$ to $15^{\circ}$, and marginally by $1.8 \%$ from $15^{\circ}$ to $20^{\circ}$.

The straight channel PCHE, though having the highest compactness, also has the highest volume. The volume of wavy channel PCHE with the pitch angle of $15^{\circ}$ is almost $44 \%$ lower than that of the straight channel PCHE. This volume is even lower than that of the OSFHE, due to the higher compactness of the wavy channel PCHE as compared to that of the OSFHE.

The lower heat exchanger volume is also desired for minimizing the heat loss to the surroundings. The external surface area of the IHX increases with the volume. As both the PCHE and OSFHE have a similar rectangular prism shape, the heat loss will be directly proportional to the IHX volume. The straight channel PCHE will have the highest heat loss, while the heat loss from the OSFHE will be similar to that from the wavy channel PCHE with the $10^{\circ}$ pitch angle. Both the $15^{\circ}$ and $20^{\circ}$ pitch angle wavy channel PCHEs will have better heat loss characteristics, and thus exhibit higher heat transfer efficiency.

\subsubsection{Guidelines for IHX Selection}

The above three - heat transfer characteristics, pressure drop, and volume/compactness - are the primary factors influencing the choice of the heat exchanger for the required duty. Based on the results of the design presented above, the $15^{\circ}$ pitch angle wavy PCHE appears to be the optimum choice due the following reasons:

1. The heat transfer coefficient is substantially higher than that obtained in the straight channel PCHE and $10^{\circ}$ pitch angle wavy channel PCHE, reducing the heat transfer area requirement.

2. The $20^{\circ}$ pitch angle wavy channel PCHE and OSFHE, while offering higher heat transfer coefficient, also incur a higher pressure drop penalty that will result in higher pumping (operating costs).

3. The compactness of the $15^{\circ}$ pitch angle wavy channel PCHE is comparable to that of $20^{\circ}$ pitch angle wavy PCHE while being significantly higher than that of other alternatives. This compactness offers advantages regarding the layout of the plant, as well as reduction in the heat loss. 
It should be noted that, apart from the above factors, other factors such as ease of fabrication, and ultimately the annualized capital and operating costs will influence the choice of the heat exchanger.

\section{Conclusions}

Compact heat exchangers are promising candidates for IHXs for Gen IV reactors such as the HTGRs and AHTRs. The wavy channel PCHE is particularly attractive, as the flow channel geometry does not allow the boundary layer to grow. The unstable boundary layer results in the formation of Görtler vortices that are advected downstream [6]. Reverse flows and eddies at the channel bends have been reported by investigators [7]. These flow effects result in increased heat transfer coefficients lowering the heat transfer area requirements for the IHX. This enhancement in the heat transfer coefficient is accompanied by a higher pressure drop across the heat exchangers, increasing the cost of pumping the fluids.

Theoretical design of various candidate heat exchangers revealed that the wavy channel PCHE with a pitch angle of $15^{\circ}$ provided optimum improvement in the heat transfer coefficient while incurring a moderate pressure drop penalty as compared to the straight channel PCHE. The pressure drop in the wavy channel PCHE was found to be substantially lower than that in the OSFHE. The OSFHE, despite a higher heat transfer coefficient, has lower compactness (heat transfer area per unit volume), which has implications regarding the equipment footprint and potential heat loss.

The comparative analysis technique presented here can also be applied for evaluating candidate heat exchangers for advanced nuclear reactors and other applications.

\section{Nomenclature}

$A_{s}$ - Heat Transfer Surface Area

$A_{f}-$ Flow Area

ch - Channel Height

$c_{p}$ - Specific Heat Capacity

$D_{h}$ - Hydraulic Diameter

$f$ - Fanning Friction Factor

$h$ - Convection Coefficient

$j$ - Colburn Factor

$k$ - Thermal Conductivity

$l$ - Fin Length

$L_{c}$ - Channel Length

$\dot{m}$ - Mass Flow Rate

$\mathrm{Nu}$ - Nusselt Number

$\Delta P$ - Pressure Drop

$P r$ - Prandtl Number

$P_{x}-$ Pitch in Span-wise Direction

$P_{y}-$ Pitch in Flow Direction

$\dot{Q}-$ Thermal Duty

$R e$ - Reynolds Number

$t_{f}$ - OSFHE Fin Thickness 
$t_{s}$ - OSFHE Plate Thickness

$t_{w}-$ Wall Thickness

$T$ - Temperature

$\Delta T_{L M T D}-$ Log Mean Temperature Difference

$\dot{Q}$ - Thermal Duty

$v$ - Mean Fluid Velocity

Greek

$\mu-$ Fluid Viscosity

$\rho$ - Fluid Density

$\phi$ - Wavy channel Pitch Angle

\section{ACKNOWLEDGEMENTS}

This research is being performed using funding received from the DOE Office of Nuclear Energy's Nuclear Energy University Programs.

\section{REFERENCES}

1. J.K. SHULTIS, R.E. FAW, Fundamentals of Nuclear Science and Engineering, Ch. 9, Taylor \& Francis, US (2008).

2. I.H. KIM, H.C. NO, "Physical Model Development and Optimal Design of PCHE for Intermediate Heat Exchangers in HTGRs," Nuclear Engineering and Design, 243, 243-250, (2012).

3. T. ISHIZUKA, Y. KATO, Y. MUTO, K. NIKITIN, T.L. NGO, "Printed Circuit Heat Exchanger Thermal-Hydraulic Performance in Supercritical CO2 Experimental Loop," International Journal of Refrigeration, 29, 807-814 (2006).

4. J. E. HESSELGREAVES, Compact Heat Exchangers: Selection, Design, and Operation, p. 156-197, Pergamon, Amsterdam; New York (2001).

5. R.M. MANGLIK, A.E. BERGLES, "Heat Transfer and Pressure Drop Correlations for the Rectangular Offset Strip Fin Compact Heat Exchanger," Experimental Thermal and Fluid Science, 10, 171-180, 1995.

6. P. GSCHWIND, A. REGELE, V. KOTTKE, "Sinusoidal Wavy Channels with Taylor-Gortler Vortices," Experimental Thermal and Fluid Science, 11, 270-275 (1995).

7. F. PRA, P. TOCHON, C. MAUGET, J. FOKKENS, S. WILLEMSEN, "Promising Designs for Compact Heat Exchangers for Modular HTRs using the Brayton Cycle," Nuclear Engineering and Design, 238, 3160-3173 (2008). 